\title{
Material de Ensino Bilingue Português/Libras para Pequenos Curiosos
}

\author{
Flaviana Teixeira ${ }^{1}$ \\ flaviana.tavares@ict.ufvjm.edu.br \\ Lucimar Daniel Simões Salvador ${ }^{1}$ \\ lucimar.salvador@ufvjm.edu.br \\ Duanne Antunes Bomfim ${ }^{1}$ \\ duannebomfim@hotmail.com \\ Josilene Duarte Nunes Ávila ${ }^{1}$ \\ lenileninha@hotmail.com \\ Raquel Mello Vianna ${ }^{1}$ \\ quelschwenck@hotmail.com
}

${ }^{1}$ Universidade Federal dos Vales do Jequitinhonha e Mucuri - Brazil

Resumo. A produção da "Coleção Pequenos Curiosos" disponibilizada na forma de audiolivros e na Língua Brasileira de Sinais (Libras) torna-se material didático acessível para estudantes da Educação Básica, com necessidades educacionais especiais. Esse material didático para apoio ao processo ensino/aprendizagem traz conhecimentos da área da biologia, química e física, adequados ao público infantil e tem como objetivo estimular o potencial cognitivo de estudantes com deficiência visual e com surdez, de forma lúdica, contribuindo para a complementação da sua formação, bem como auxiliar o aprendizado da libras por pessoas ouvintes. Tais produtos encontram-se disponíveis gratuitamente para compartilhamento com interessados.

Palavras-chave: crianças; libras; popularização da ciência

\section{Portuguese Bilingual Teaching Material / Libras for Little Curious}

Abstract. The production of the "Little Curious Collection" made available in the form of audiobooks and the Brazilian Language of Signs (Libras) becomes accessible didactic material for students of basic education with special educational needs. This didactic material to support the teaching / learning process brings knowledge from the field of biology, chemistry and physics, suitable for children and aims to stimulate the cognitive potential of visually impaired students with deafness, in a playful way, contributing to the complementation of their training, as well as assisting the learning of libras by hearing people. Such products are freely available for sharing with interested parties.

Keywords: children; libras; popularization of science 


\section{Introdução}

A Educação Inclusiva constitui um paradigma educacional fundamentado na concepção de direitos humanos, que conjuga igualdade e diferença como valores indissociáveis (BRASIL, 2008). Como fruto dos movimentos de luta da sociedade pelo direito de todos à educação, a Educação Inclusiva vem se destacando no panorama educacional mundial, devido à crescente demanda apresentada nos últimos anos.

Sendo assim, o poder público promulga, através de leis e políticas públicas educacionais, ações para a inclusão das pessoas com deficiência, como acessibilidades arquitetônicas e comunicacionais, com a finalidade de garantir acesso e autonomia destes "mediante a supressão de barreiras e de obstáculos nas vias e espaços públicos, no mobiliário urbano, na construção e reforma de edifícios e nos meios de transporte e de comunicação" (BRASIL, 2000).

Nesta perspectiva, o governo federal, através da Lei de Diretrizes e Bases da Educação (LDB) n. 9.394, de 1996, trata no capítulo V “da Educação Especial” artigo 59 que os sistemas de ensino assegurarão aos educandos com necessidades especiais, no item I "currículos, métodos, técnicas, recursos educativos e organização específicos, para atender às suas necessidades" (LDB, 1996).

Um destes recursos educativos referenciados pela LDB é legitimado com a aprovação da Lei n. 10.436 de 2002, conhecida como "Lei de Libras" que reconhece a Língua Brasileira de Sinais (Libras) como meio legal de comunicação e expressão das comunidades de pessoas surdas do Brasil, ademais traz em seu artigo $2^{\circ}$ que o poder público em geral e empresas concessionárias de serviços públicos devem apoiar o uso e a difusão da Libras como meio de comunicação objetiva (BRASIL, 2002).

Com a finalidade de regulamentar tal lei, promulga-se o Decreto n. 5.626 de 2005 trazendo em seu capítulo IV, item VIII, que as instituições federais de ensino devem "disponibilizar equipamentos, acesso às novas tecnologias de informação e comunicação, bem como recursos didáticos para apoiar a educação de alunos surdos ou com deficiência auditiva" (BRASIL, 2005).

Para tal inclusão linguística as instituições federais de ensino da educação básica e da educação superior devem incluir, em seus quadros, em todos os níveis, etapas e modalidades, o tradutor e intérprete de Libras - Língua Portuguesa, para viabilizar o acesso à comunicação, à informação e à educação de alunos surdos, além de dispor de materiais bilíngues para acesso das pessoas surdas aos conteúdos ministrados (BRASIL, 2005).

A produção de materiais bilíngues demanda pesquisa e atuação de profissionais capacitados para tal elaboração, uma vez que se trata de adaptações e interpretações de duas línguas de modalidades distintas, a Língua Portuguesa de natureza oral e auditiva e a Língua de Sinais espacial e visual, além de levar em consideração que tratará de um material bicultural, devendo estar de acordo com as duas culturas em questão (SALLES et al, 2004).

Sendo assim, a Universidade e as demais Instituições de Ensino Superior precisam aprender, com a convivência, por meio de um processo interativo, a trabalhar com a deficiência. A permanência, com sucesso, do aluno no ambiente educacional implica a possibilidade de usufruir dos equipamentos e condições necessárias à equiparação das condições oferecidas aos demais alunos (BASSO; CAPELLINI, 2012).

A produção de materiais bilíngues em ambientes acadêmicos ainda tem sido uma área pouco explorada no Brasil, sendo melhor tratada em pesquisas de pós-graduações como a de Basso e Capellini (2012) da Universidade Federal de São Carlos, em que através da busca de acessibilidade comunicacional, o trabalho tornou acessível em 
Libras a obra $O$ Penuginha de Luiz Vitor Martinello, com a finalidade de colaborar no ensino de alunos surdos na educação infantil (BASSO; CAPELLINI, 2012).

Trabalhos desenvolvidos em projetos de extensão também têm o foco na produção de materiais bilíngues para surdos, como o projeto de Teixeira e Baalbaki (2014) "Recursos e materiais para o ensino de português para alunos surdos", tendo como objetivo a elaboração de materiais didáticos que atendam às necessidades linguísticas dos surdos, por meio da oferta de um espaço de discussão para os graduandos e professores de língua portuguesa, considerando, em uma perspectiva de educação bilíngue, a língua brasileira de sinais (Libras) como a primeira língua do aluno surdo e a língua portuguesa como sua segunda (TEIXEIRA; BAALBAKI, 2014).

As dificuldades enfrentadas nos sistemas de ensino para promover a educação inclusiva, trazem à tona a necessidade de confrontar as práticas discriminatórias e criar alternativas para superá-las. É preciso repensar o papel social das escolas, a organização dos espaços escolares e o desenvolvimento de um trabalho pedagógico efetivo, implicando uma mudança estrutural e cultural da escola para que todos os estudantes tenham suas especificidades atendidas (BRASIL, 2008).

Por ser um processo que requer a reestruturação de aspectos culturais e das práticas vivenciadas no contexto escolar, a inclusão de educandos com necessidades especiais na educação básica e superior, tem se constituído um desafio aos educadores e pesquisadores. Exige, sobretudo, ações políticas comprometidas com a construção de estratégias de ensino/aprendizagem que atendam à diversidade de alunos ingressantes na educação formal e contribuam para a sua permanência e sucesso escolar.

Necessário se faz, buscar meios para estimular a participação e aprendizagem dos estudantes com Necessidades Educacionais Especiais (NEE), na sala de aula e no Atendimento Educacional Especializado (AEE), promover mudanças nos processos pedagógicos e curriculares, de modo a atender às diferenças (DAMÁZIO, 2007).

Nesse contexto, a universidade como um dos espaços de produção e socialização do conhecimento tem como um de seus desafios, desenvolver programas sociais relevantes, capazes de contribuir para a solução de problemas, superando distintas modalidades de exclusão (MELLO et al., 2009).

A produção da "Coleção Pequenos Curiosos" disponibilizada na forma de audiolivros e na Língua Brasileira de Sinais (Libras) produzida na Universidade Federal dos Vales do Jequitinhonha e Mucuri - UFVJM, torna-se material didático acessível para estudantes da Educação Básica, com necessidades educacionais especiais. Esse material didático para apoio ao processo ensino/aprendizagem traz conhecimentos da área das ciências, adequados ao público infantil e tem como objetivo estimular o potencial cognitivo de estudantes com deficiência visual e com surdez, de forma lúdica, contribuindo para a complementação da sua formação.

Essa ação traduz o compromisso da Universidade de integração com as escolas de Educação Básica, no sentido de fortalecer as políticas públicas para a inclusão de estudantes com necessidades especiais, na medida em que busca contribuir, por meio de desenvolvimento de programas e projetos de extensão, para a promoção, socialização, divulgação e acesso ao conhecimento científico.

\section{Primeiros Passos: Elaboração da Coleção de Livros Pequenos Curiosos}

O Projeto Pequenos Curiosos iniciou suas atividades no município de Diamantina - MG, na Universidade Federal dos Vales do Jequitinhonha e Mucuri, em 
2012. Tem como objetivo a promoção, divulgação e socialização do conhecimento científico ao público infantil por meio da elaboração de livros.

A produção originou-se de temas apresentados por crianças na faixa etária de oito a doze anos de idade, que se referiam a dúvidas e curiosidades relacionadas ao seu cotidiano. As explicações e esclarecimentos foram feitos por professores universitários, baseando-se em áreas da ciência como a química, a física e a biologia. Após essa fase, as crianças aqui denominadas "Pequenos Curiosos" elaboraram desenhos representativos, os quais foram adicionados aos demais dados e organizados no formato de livros infantis.

O trabalho ora descrito visou ampliar a divulgação da ciência em escolas do Vale do Jequitinhonha e do Vale do Mucuri, ambos localizados no estado de Minas Gerais, Brasil.

A produção gerada pode ser considerada um modo de romper as muitas barreiras que separam as crianças dos conceitos científicos.

A seguir apresenta-se uma síntese dos exemplares da coleção Pequenos Curiosos, bem como na figura 1 pode-se visualizar a capa destes dez exemplares.

O volume 01, intitulado $O$ Mistério do Halo Solar, traz a explicação do surgimento de um arco-íris redondo em volta do sol, abordando conteúdo de física.

O volume 02, Ácido na Cebola?, ocupa-se em saciar a curiosidade das crianças sobre porquê choramos quando picamos cebola, enfocando conteúdo da química.

O volume 03, Fogos de Artifício, explica o porquê os fogos de artifício são coloridos, tendo como base a química.

Já o volume 04, O Doce do Algodão Doce, por meio do esclarecimento de como se faz algodão doce, aborda conceitos físicos.

No volume 05, O Segredo do Bolo, a história desvenda o que faz o bolo crescer e ficar fofinho, apresenta reação química.

O volume 06, Pulseiras de Luz, objetiva esclarecer o porquê das pulseiras de neon brilharem no escuro, também tem como base a química.

Já o volume 07 , Petróleo no Pré-Sal, trata de conhecer um pouco mais sobre o petróleo e apresenta um pouco de geologia e biologia.

No volume 08, Sabonete Colorido com Espuma Branca?, a explicação de o porquê os sabonetes cor de rosa, amarelo, verde e azul produzem espumas brancas e não coloridas como eles. O conteúdo base do esclarecimento é a física.

No volume 09, Micróbios, aborda-se o motivo pelo qual devemos lavar nossas mãos antes das refeições e também, sobre a utilidade de alguns microorganismos em nossa atualidade. A base da explicação vem da biologia.

E o volume 10, Salvem os Sapos, apresentar informações sobre os sapos, tendo um conteúdo biológico. 
Figura 1 - Capas dos 10 livros elaborados no projeto Pequenos Curiosos
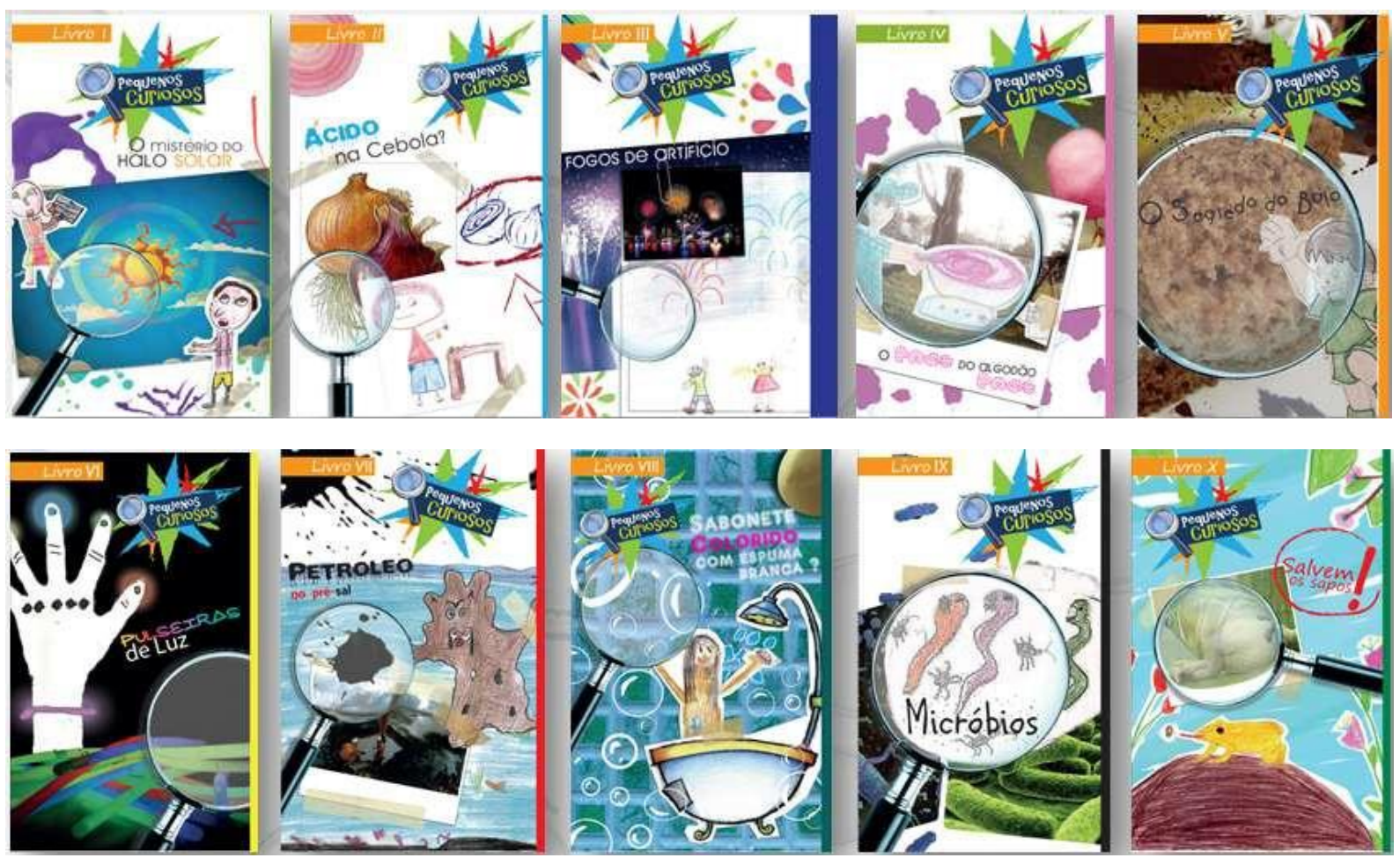

Um relato mais detalhado sobre o desenvolvimento dos livros foi realizado por Teixeira (2016). A citada produção pode ser acessada gratuitamente em www.ufvjm.edu.br/sites/pequenoscuriosos.

\section{Caminhando e Ouvindo: Audiolivros Pequenos Curiosos}

Após o desenvolvimento dos livros surgiu a ideia de desenvolver audiolivros, de forma a atingir um público maior.

Um audiolivro é a versão artística de um livro de papel. Tem como uma de suas características, a dramatização da leitura, às vezes feita por mais de um locutor, contando com sonoplastia (trilha sonora e efeitos especiais), ambientando a obra e orientando a interpretação (Jesus, 2011). Desta forma o audiolivro surge como alternativa para os leitores, podendo se constituir também em valioso instrumento para a inclusão social. Os livros falados são editados em computador, utilizando dispositivos de captura de som, software de edição e um drive gravador de CD.

O atual trabalho é uma forma de disseminação da Coleção Pequenos Curiosos em outro formato: áudio. Trata-se de uma opção a mais para o leitor e pode configurar como uma opção para o deficiente visual.

Planejou-se e executou-se o roteiro de gravação utilizando-se da técnica de adaptação de livros, treinamentos de postura em voz, dicção e dramatização, com suporte do programa de edição Cool Edit Pro para a gravação e edição das vozes, bem como inclusão da sonoplastia (Vieira; Salvador, 2015). A figura 2 traz a capa do CD bem como o adesivo impresso sobre o mesmo. 
Figura 2 - Capa e silk do CD contendo os audiolivros da Coleção Pequenos Curiosos.
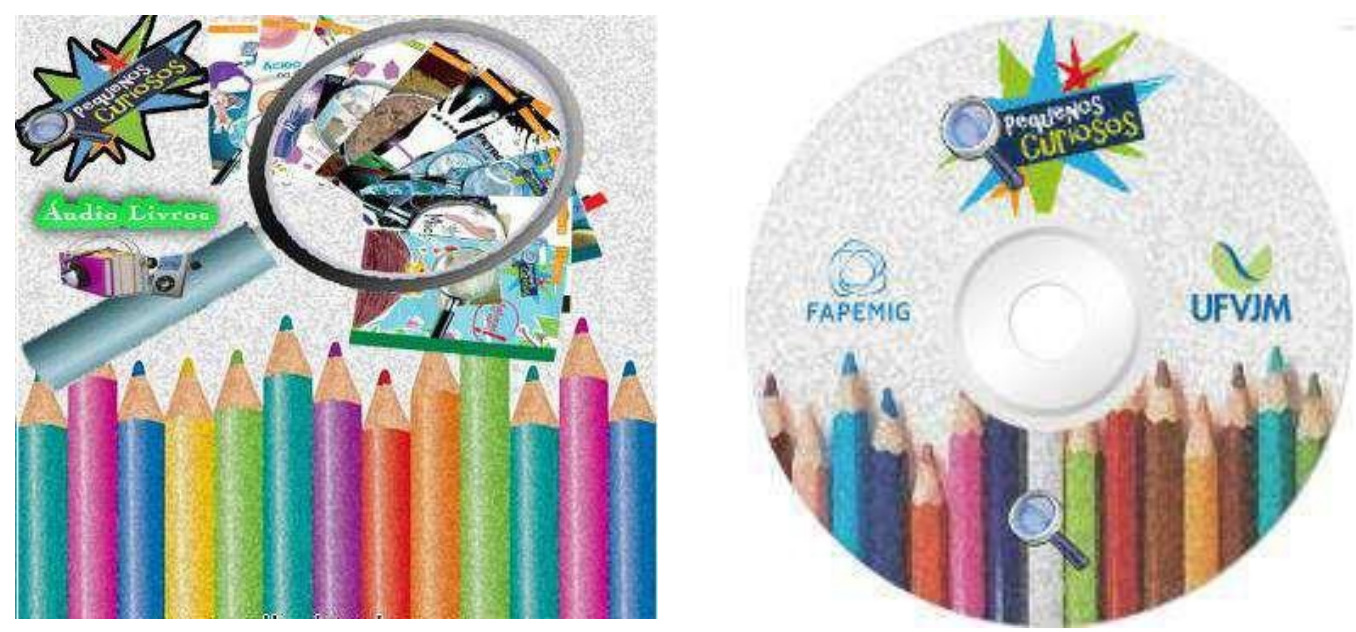

A produção dos audiolivros contou com a colaboração de várias pessoas na interpretação das vozes dos personagens que participaram das dez historinhas, na interpretação musical e no trabalho de edição.

Os livros foram transformados em áudios de forma bastante atraente para o ouvinte do material produzido. Além da interpretação e locução das vozes, foram inseridos fundos musicais e sons onomatopeicos.

Os audiolivros podem ser ouvidos gratuitamente em www.ufvjm.edu.br/site/pequenoscuriosos.

\section{Caminhando e "Vendo Vozes": Produção dos Vídeo-Livros em Português/Libras}

Os vídeos foram elaborados contando com a interpretação em Português/Libras feita por uma intérprete, sob a supervisão de dois professores responsáveis pela disciplina de Libras da Universidade Federal dos Vales do Jequitinhonha e Mucuri UFVJM (Figura 03).

Figura 03 - Interprete de Libras realizando a adaptação dos textos
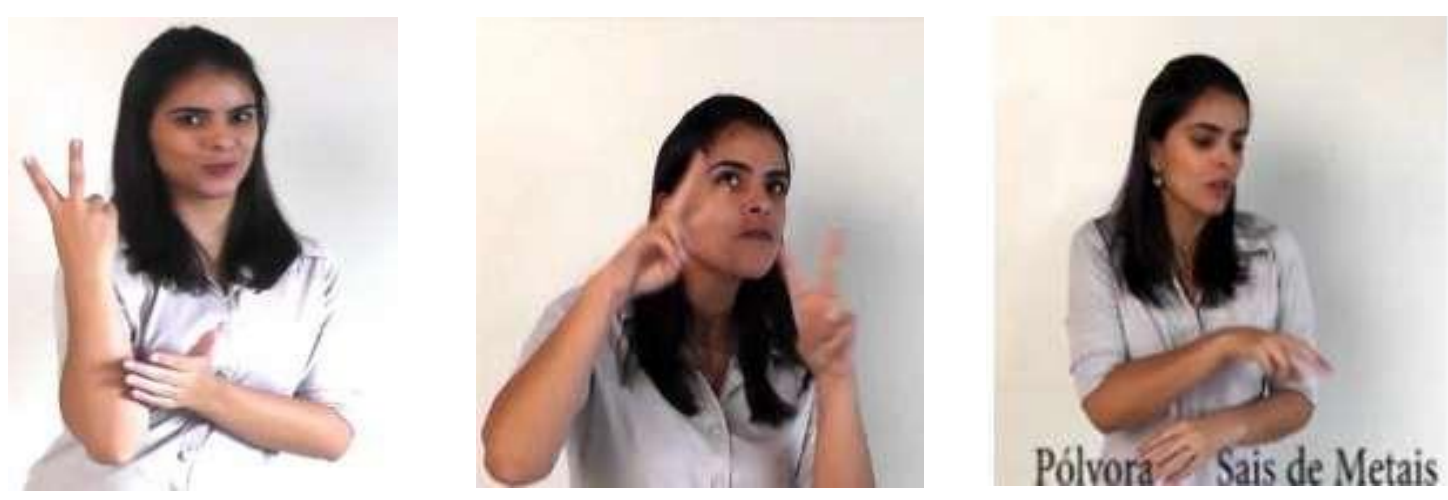
Após estudo dos textos, foi feita a interpretação e seguiu-se para a filmagem. $\mathrm{Na}$ sequência, fez-se a edição das imagens da intérprete colocando as ilustrações das crianças ao fundo do vídeo e inserindo-se, também, as vozes e a opção de legenda escrita. A edição foi realizada no Adobe Premiere.

Produziu-se um DVD contendo dez vídeos bilíngues que retratam a obra impressa, anteriormente publicada, além da produção de áudios referentes às historinhas relatadas (Figuras 04 e 05).

Figura 04 - Capa e silk do DVD contendo os videolivros da Coleção Pequenos Curiosos
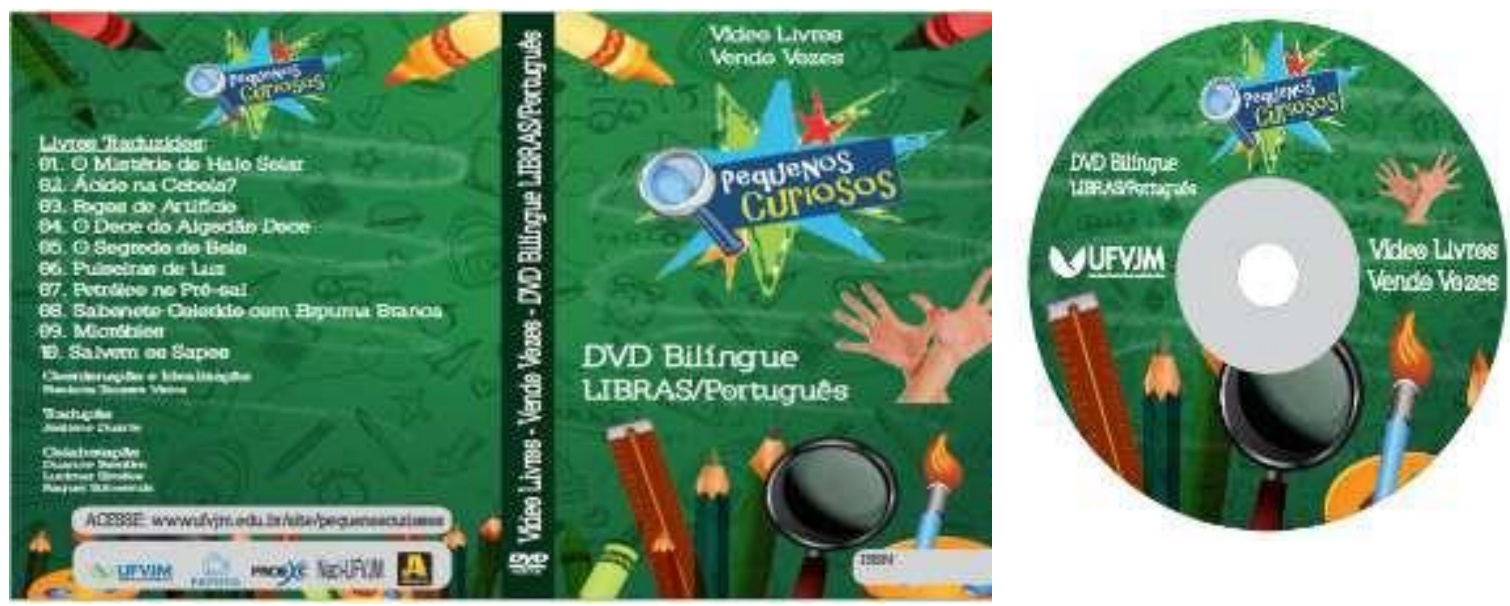

Uma das cenas produzidas pode ser observada na figura a seguir.

Figura 05 - Uma das cenas de interpretação em Libras pela intérprete em um dos vídeos produzidos.






\section{Divulgação}

A divulgação da produção bilíngue português/Libras é disponibilizada gratuitamente, bem como foram as demais produções da Coleção Pequenos Curiosos, para todas as escolas estaduais de todos os municípios do Vale do Jequitinhonha e do Vale do Mucuri em Minas Gerais. Segue o mapa dos vales para melhor visualização da área de abrangência do projeto.

Figura 06 - Mapa de Minas Gerais evidenciando o Vale do Jequitinhonha e o Vale do Mucuri.

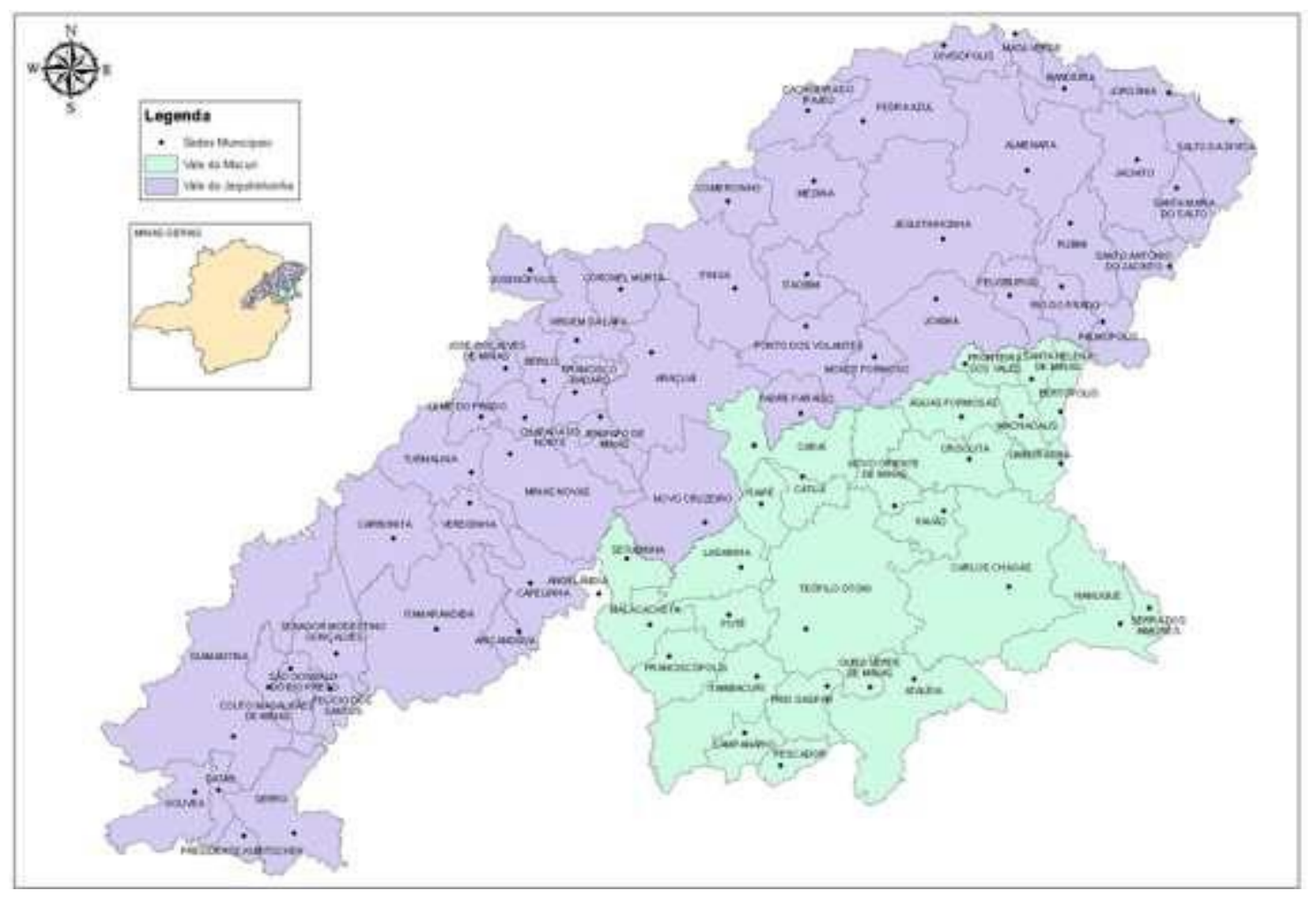

Fonte: Adaptado de http://culturaneocruzeirense.blogspot.com.br/2011/09

\section{Considerações Finais}

É indiscutível o papel da Universidade enquanto locus de produção e socialização do conhecimento, bem como seu compromisso social de disseminá-lo de modo a beneficiar a comunidade em seu entorno, contribuindo assim para a transformação da sociedade.

Nesse sentido, o material didático pedagógico produzido com a coleção Pequenos Curiosos, no formato impresso, em áudio e em vídeo, divulga o conhecimento científico facilitando o acesso de crianças com necessidades especiais, auxiliando a sua inclusão no processo de aprendizagem. As histórias, abordadas de forma lúdica, pretendem atingir o público infantil e foram desenvolvidas a partir de temas originados das curiosidades apresentadas por ele, podendo também ser desfrutadas pelos adultos. 
Os audiolivros podem ajudar a desenvolver a atenção e imaginação. Além de serem instrutivos, também podem ser considerados uma excelente forma de entretenimento.

Os vídeo-livros bilíngues podem auxiliar os surdos, pessoas com baixa audição e ainda auxiliar o aprendizado das pessoas ouvintes, a fim de melhor se comunicarem com estes.

Trata-se também da primeira produção do gênero elaborada pela UFVJM e, com esse material, espera-se poder contribuir com o processo ensino/aprendizagem despertando o interesse das crianças pelo conhecimento.

\section{Agradecimentos}

-Fundação de Amparo à Pesquisa em Minas Gerais - FAPEMIG

-Pró-Reitoria de Extensão e Cultura - Proexc da Universidade Federal dos Vales do Jequitinhonha e Mucuri - UFVJM

-Núcleo de Acessibilidade - Naci da UFVJM.

-Produtora Allegro - Diamantina - MG. Diretor Felipe M. Costa.

\section{Referências Bibliográficas}

BASSO, S. P. S.; CAPELLINI, V. L. M. F. Material didático para alunos surdos: a literatura infantil em Libras. Revista Eletrônica de Educação, v. 6, n. 2, 2012.

BRASIL. Lei n. 10.098 de 19 de dezembro de 2000. Estabelece normas gerais e critérios básicos para a promoção da acessibilidade das pessoas portadoras de deficiência ou com mobilidade reduzida, e dá outras providências. Brasília, 2000.

. Lei n. 10.436 de 24 de abril de 2002. Dispõe sobre a Língua Brasileira de Sinais - Libras e dá outras providências. Brasília, 2002.

Decreto n. 5.626 de 22 de dezembro de 2005. Regulamenta a Lei no 10.436, de 24 de abril de 2002, que dispõe sobre a Língua Brasileira de Sinais - Libras, e o art. 18 da Lei no 10.098, de 19 de dezembro de 2000. Brasília, 2005.

. Lei de Diretrizes e Bases da Educação Nacional: Lei n. 9.394, de 1996. LDB. Brasília: Secretaria de Edições Técnicas (1997).

- Ministério da Educação. Política Nacional de Educação Especial na perspectiva da Educação Inclusiva. MEC; SEESP; 2008. Disponível em: http://portal.mec.gov.br/arquivos/pdf/politicaeducespecial.pdf. Acesso em: 25/05/2015.

DAMÁZIO, M. F. M. Atendimento Educacional Especializado: pessoa com surdez. In: Formação Continuada a Distância de Professores para o Atendimento Educacional Especializado. Brasília, 2007. 
JESUS, P.S. Livros sonoros: audiolivro, audiobook e livro falado. 2011. http://www.bengalalegal.com/livros-sonoros (acesso em setembro de 2016)

MELlO, A. F. de; ALMEIDA FLHO, N.; JANINE RIBEIRO, R. Por uma universidade socialmente relevante. Atos de Pesquisa em Educação, v. 4, n. 3, p.292302, 2009.

SAlleS, H. M. M. L.; FAULSTICH, E.; CARVALHO, O. L. Ensino de língua portuguesa para surdos: caminhos para a prática pedagógica. Secretaria de Educação Especial; Programa Nacional de Apoio à Educação de Surdos - Brasília, DF: MEC; SEESP, 2004.

TEIXEIRA, F.T.V. Pequenos Curiosos: participação de crianças na ilustração de livros infantis. Em Extensão, Uberlândia, v. 15, n. 1, p. 72-88, jan./jun. 2016.

TEIXEIRA, V. G.; BAALBAKI, A. C. F. Novos caminhos: pensando materiais didáticos de língua portuguesa como segunda língua para alunos surdos. Em Extensão, v. 13, n. 2, p. 25-36, 2014.

VIEIRA, F.T.; SALVADOR, L.D.S. Do Papel ao Som: Áudiolivros Pequenos Curiosos. Anais da IV Semana da Integração, Ensino, Pesquisa e Extensão. Universidade Federal dos Vales do Jequitinhonha e Mucuri, Diamantina - MG, p.158. 2015. 